\title{
Introducing Interactive Documentary in the Context of Critical Media Education
}

\author{
DANAI MIKELLI \\ Coventry University
}

\begin{abstract}
This paper provides an overview of my doctoral research project, concerning the educational uses of interactive documentary. It also discusses the pedagogical possibilities and limitations of Mozilla's Popcorn Maker, which is a web application for the creation of interactive stories and consists the main tool for my fieldwork, involving young people in a series of workshops with the aim to produce their own interactive documentaries.
\end{abstract}

My research is theoretically anchored to the work of Brazilian educator Paulo Freire and is aligned with the model of Critical Media Education. My research questions investigate the ways in which young people engage with interactive documentaries and the potential of such practices to raise critical consciousness, as defined by Freire (1970). Gifreu (2012) sees interactive documentary as a medium that offers 'experiences that combine an entertainment with a didactic and/or educational dimension', however its position within Critical Media Education has not been yet discussed.

\section{KEYWORDS}

Interactive documentary; critical media education; action research; Mozilla Popcorn Maker.

\section{Introduction}

'The whole point of interactive documentary is to make people to be involved like they want to click on this section to see what it is about, they want to click on that or they want to go to the next one, so yes, it did change my views on what I thought interactive documentary was before and how I'd want it to be when I make it.'

- Media Production student

This paper is divided in two parts. The first part presents an overview of my $\mathrm{PhD}$ research project and focuses on its theoretical underpinnings, as well as the chosen methods for data collection and analysis. I am interested in examining how young people, 
especially from underprivileged backgrounds, engage with interactive documentary practices, thus arguing towards a 'New Media Pedagogy of the Oppressed'. This approach is rooted in the ideas of educator Paulo Freire, who championed the need for critical pedagogy in Latin American societies, at a time of political struggles and social transformation.

The second part of this paper provides an evaluation of the possibilities and limitations of Mozilla's Popcorn Maker as a tool in the hands of Critical Media pedagogues. The Popcorn Maker is a free web application for enhancing, remixing and sharing web videos. The application was tested in the context of a Media Production module at Coventry University, encouraging first year students to experiment with different media platforms. The students used the Popcorn Maker in order to create interactive documentaries and then discussed their experience in a focus group interview.

\section{Background}

My $\mathrm{PhD}$ research project is positioned within the tradition of Critical Media Literacy. This pedagogical approach promotes the use of diverse types of media in order to question the roles of media in society and the multiple meanings of messages. According to Douglas Kellner and Jeff Share (2007, 3), the changes in technology and society ask for the development of Critical Media Literacy in order to enable learners to increase their participation as democratic citizens. The authors suggest that this model of Media Education could empower marginalized or misrepresented people by giving them the tools to express their concerns.

This model is also argued to provide the basis for a 'political project for democratic social change' (Kellner \& Share 2007, 8). As I am interested in the potential of Media Education within political environments, my $\mathrm{PhD}$ fieldwork will focus on different educational contexts and emphasize the suitability of this particular approach ${ }^{1}$.

The participants, mainly young people from socially and economically disadvantaged areas, will be introduced to the basic principles of interactive documentary practice through a series of workshops, each of which will last two months. They will be assigned to choose various aspects of their society and work in teams in order to document them. For the needs of filming, the young people will use lightweight cameras, or mobile phone cameras. Tutorials in the Popcorn Maker will complete the learning process. At the end of the workshops, all projects will be shared on an online platform, thus encouraging further dialogue. The freedom of dissemination offered by web based interactive media will allow the work of the young people to become known by users globally, thus giving them the opportunity to engage with ideas and participate in the debates, regardless of their location.

Douglas Kellner and Gooyong Kim (2009) point out that new media technologies

1 My fieldwork is still at the stage of planning and involves collaboration with three partner organisations, which will endorse a series of interactive documentary workshops over a period of 9 months. 
challenge the institutionalization of education, as they make possible decentralized and interactive communication and a participatory model of culture and technology. The authors emphasize how new media, combined with a transformative critical pedagogy, can realize the Internet's potential for democratization. They see the Internet as a new field for the conjuncture of education and democracy, as it provides opportunities for an expanded flow of information. They also call for new critical media pedagogies that will enable students to use new media for progressive pedagogical and political goals.

In the white paper 'Confronting the Challenges of Participatory Culture: Media Education for the 21st Century', published in 2006, Henry Jenkins and a team of coauthors from the MIT Comparative Media Studies Programme suggested a new framework for media education in the context of Participatory Culture, which embraced the latest advancements in the media landscape and focused on the educational system of the United States. The authors provided a definition for Participatory Culture, highlighting the members' social connection with one another (Jenkins et al., 2006).

Jenkins (2011) expands on the concept of Participatory Culture, where most people have the capacity to take control of the media and influence the circulation of ideas and images. He believes that we do not yet live in a fully participatory culture, but that our culture is more participatory now than it was before networked computing. The need for media education today is pressing, as it can enable learners to understand the changes in media technologies, alongside the practices and institutions that affect the production of media (Jenkins, 2011). He concludes that media education should engage with the practices of everyday life, which resonates with Favero's (2013) idea about interactive documentary inviting us to engage with the physicality and socialness of everyday life.

David Buckingham (2010) questions some of the assumptions that accompanied the appearance of new media, in particular their potential to bring fundamental change and their implications in pedagogy. He argues that Media Education 2.0 should conform to the traditional principles of Media Education and that creative practice needs to be supported by critical analysis. For him, Web 2.0 promotes reflexivity, which can be achieved if students take a step back from their immediate experience.

Last but not least, Stuart Poyntz (2006) emphasizes the role of critical practice in media education, thus addressing society's promise of democratic change. He also discusses new media in the context of media education and explains how students may benefit from the possibilities of the Internet, including collective intelligence and making connections in digital media environments (Poyntz, 2011).

\section{Why Pedagogy of the Oppressed now?}

The critical model of Media Education is in harmony with the educational legacy of Brazilian educator Paulo Freire. Freire published his seminal book Pedagogy of the Oppressed in 1970. In this book, he rejected what he called the 'banking' concept of education, a metaphor he used in order to describe the traditional educational system, 
according to which knowledge is deposited from one (the teacher) to another (the student). He suggested a 'problem-posing education', which enables teachers and students to become subjects of the educational process and also enables people to overcome their false perception of reality.

At the heart of Freire's pedagogy lies the concept of 'Conscientization', which refers to raising the awareness of the oppressed regarding their state of oppression. This term implies learning to perceive social, political and economical contradictions and to take action against the oppressive elements of reality (Freire 1970,17). It is this understanding of raising consciousness that is central to my doctoral research, and I would like to explore the possibilities of interactive documentary as a means for helping young people not only to understand the situations of oppression, but also to act towards changing them.

As Rhonda Hammer (2009) explains in her paper 'This Won't be on the Final, Reflections on Teaching Critical Media Literacy', Freire's critique of the banking method is an apt description of the prevailing mode of teaching in many contemporary universities and schools. I, as well, consider Pedagogy of the Oppressed to be very timely. Freire wrote about Latin American societies more than sixty years ago, however, the similarities with many European countries today are striking. An interesting portrait of crisis-stricken Europe is provided in the book Philosophy and Resistance in the Crisis by Costas Douzinas (2013). Douzinas argues that we have entered what he calls the Age of Resistance, a time of protests, occupations and uprisings. The desire for radical change was manifested in different parts of the world. These events could not have been predicted by standard political science, although they signaled a fundamental shift in the politics of the 21st century (Douzinas, 2013).

This unrest in many countries and the need for change is also reflected in the use of new media. Paolo Favero (2013) discusses the suitability of interactive documentaries to address social issues and encourage social change. Social and political changes in today's capitalist societies are aligned with these new media practices.

\section{Exploring the idea of a New Media Pedagogy of the Oppressed}

The changing nature of the media landscape, alongside new social complexities, has had an impact on the way knowledge is produced. There is a need to address issues of interactivity, audience participation, networking, collaborative systems, the role of media producers and the different modes of media distribution. Media education should also be reconsidered on this basis and this is the focus of my $\mathrm{PhD}$ research.

My research project is aligned with Open Media and Open Pedagogies, which are distinctive academic directions for the Department of Media at Coventry University. Open Media embrace Open Technologies, Sustainable Professional Practice, Engagement and Visible Media and Communication. Peter Woodbridge (2011) defines Open Pedagogies as educational practices aiming to impact and involve a much broader range 
of participants in educational communities and suggest a process of teaching and learning which is collaborative, media-enabled and expanded. This approach makes use of innovative and collaborative learning styles and encourages the reflective use of new technologies in order to develop extended communities of learning.

Open Pedagogies are useful for addressing my research questions, because the tool for my fieldwork, interactive documentary, promotes issues of openness and cultivates collaborative ethos. Although my studies in Film and Documentary focused on more traditional practices, I discovered this new cultural form while teaching Media in Greece two years ago.

\section{Understanding interactive documentary}

Interactive documentary is a rapidly evolving field, which needs to be positioned within a culture of New Media. According to Lev Manovich (2001, 19), the world in 2001 was in the middle of a New Media revolution, as all culture shifted to computer-mediated forms of production, distribution and communication. For him, New Media represent a convergence of two different historical trajectories, that of computing and of media technologies, and the result is New Media: graphics, moving images, sounds, shapes, spaces, and texts that have become computable.

One of the first scholarly writings in the field of interactive documentary is provided by Dayna Galloway, Kenneth Mcalpine and Paul Harris (2007) in the paper 'From Michael Moore to JFK Reloaded: Towards a working model of Interactive documentary'. The authors illustrate traditional documentary's historical background and explore interactivity in the context of interactive entertainment titles, film and television. They provide a definition for interactive documentary as 'any documentary that uses interactivity as a core part of its delivery mechanism' and raise issues about the changing role of the documentary filmmaker.

Arnau Gifreu (2011) provides a more complex definition of interactive documentaries as 'interactive online/offline applications, carried out with the intention of representing reality with their own mechanisms, including navigation and interaction modalities, depending on the degree of participation under consideration'. Added to this, he examines the educational uses of interactive documentary and analyses its potential as a new learning system, arguing that it 'offers experiences that combine entertainment with a didactic and/or educational dimension' (Gifreu, 2012). The advantages of digital teaching and learning systems include interactivity, collaborative learning, multidirectionality and freedom of publication (Gifreu, 2012).

Manovich (2001) illuminates a different aspect of interactive media and comments on what he calls the myth of interactivity. He associates interactive media with the demand of modern society for standardization, since users are asked to follow 'the mental trajectory of the new media designer' (Manovich, 2001). His claims are legitimate, however, I consider interactive documentary to be ideal for the purposes of my 
educational research project. I see interactivity as an opportunity for young people to raise their consciousness about their selected topics, while having fun. Interactive tools pose both advantages and disadvantages for educational purposes. This will be illustrated through the example of the Popcorn Maker in the second part of this paper.

\section{Methods}

The method of action research encompasses my fieldwork, as I will be teaching the young people how to make their interactive documentaries. Action research is a form of participatory democratic educational research for educational improvement, which is carried out by practitioners into their own practices (Kemmis, 1988).

Kemmis and McTaggart (2005) trace the origins of participatory action research in the connection between critical emancipatory action research and participatory action research that had developed in the context of social movements in the developing world, championed by people like Paulo Freire. For the authors, participatory action research is a social process, which is collaborative, emancipatory, critical, reflexive and aims to transform theory and practice.

There has been criticism on the political nature of emancipatory action research, as opposed to other methods focusing more on the personal and professional development of educational practitioners. Carr and Kemmis (2009) challenge the assumption that educational action research can be anything other than "political" and argue that education is politics conducted by other means.

The authors believe that education can only be understood as part of the general process of social reproduction: the social process by which new generations are initiated into the language, roles and relationships in order to become members of a society. Education serves a transformative function by providing new generations with the forms of consciousness and modes of social relationships necessary to participate in changed forms of social life.

The authors conclude by seeing action research as personal, professional and political, as it requires the existence of educators (personal dimension) with a commitment to practising education, the existence of institutions for the conduct of education (professional dimension) and the existence of traditions of education (political dimension) in which generations of educators reach evolving understandings of what education is. They argue in favour of a critical approach, which explores the relationships between these three faces of educational action research, relationships between individual and collective self-transformation, the transformation of the educational profession and institutions and the transformation of society in which one participates as an educator and a citizen.

During my $\mathrm{PhD}$ fieldwork, data will be collected in the form of the interactive documentaries created by the young people themselves, video elicitation interviews with 
the young people and my own research diary. The thematic content of the interactive documentaries will be analyzed on the basis of the corresponding participants' verbal explanations (recorded during video elicitation interviews). Field notes will used to frame the educational process and contribute to the creation of a set of proposals for teaching and learning with interactive documentary. In this respect, the principle of triangulation is being considered. Sagor (2011) suggests that the use of the triangulation matrix can build a case worthy of confidence, as a triangulated data-collection plan can offer findings characterized by validity and reliability. Validity refers to whether the data reflect the phenomena they claim to and reliability refers to the accuracy of the data.

From the beginning of the workshops, I will be keeping a diary reflecting on the educational process, thus using an ethnographic tool. Ethnography is based on the assumption that what people say and do is consciously and unconsciously shaped by the social situation (Wilson, 1977). Sara Delamont and Paul Atkinson (1980) discuss the 'ethnography' of schooling as research on and in educational institutions based on participant observation and recordings of everyday life in naturally occurring settings.

Judith Goetz and Margaret Lecompte (1984) define educational ethnography as an investigative process and approach to studying problems in education, which has an interdisciplinary character, as it has been practiced by researchers from different traditions. Appropriate use of ethnographic design in educational research has been limited by a number of factors, for example most educational researchers receive their training through the discipline of psychology or anthropology (Goetz and Lecompte, 1984). The authors argue that educational ethnography has the purpose to provide rich data about the contexts, activities and beliefs of participants in educational settings.

Last but not least, video elicitation interviews will be carried out at the end of the workshops. Video and film have featured in the development of social research within sociology, anthropology, education and psychology, as Carey Jewitt (2012) points out in the paper 'An introduction to Using Video for Research'. Video elicitation can be used to prompt discussion, stimulate recall and provide a basis for reflection (Jewitt, 2012). This method was selected in order to encourage the students to discuss their final documentaries and the ways in which these have influenced their awareness of the selected topics.

The use of visual data in educational research, and action research in particular, is worth further investigation. Sheri Klein and Faith Agostinone-Wilson (2012) point out that visual methods in educational research are mainly used by researchers who are interested in understanding their topics 'through multiple ways, including the visual'. These methods allow researchers to establish a 'critical dialogue' between participants, communities and larger communities of practice (Klein and Agostinone-Wilson, 2012). Critical dialogue, as promoted by Freire, is a key concept in my research project, therefore the employment of visual methods would be aligned with the ideas underpinning my research.

Buckingham (2009) provides a critique of visual research methods in media research and 
challenges the suitability of these methods to provide insights in the participants' feelings and thoughts. He finds this approach problematic as it does not consider the role of the researcher, the formal characteristics of the media that participants use and the participants' understanding of the aims of research itself. Buckingham emphasizes the need for more reflexive understanding of 'how research itself establishes positions' from which participants can express themselves, and I will take this point into consideration for the analysis of my findings. Buckingham also stresses the need for analyzing all data in the context they need to be collected, the social relationships between participants and the resources they use. Ethical considerations should be addressed in 'the wider social contexts, in which research is conducted, distributed and used'.

\section{The Popcorn Maker}

The Popcorn Maker ${ }^{2}$ is a free, web based software which was launched in 2012 and allows the creation of interactive stories without the need of a team of developers. Users are given the freedom to experiment with interactive media using video, audio and images from the web.

The Popcorn Maker is part of Mozilla Webmaker, which promotes the Foundation's Web Literacy campaign. Mozilla Webmaker's moto is 'we teach the web' and provides a different approach to education. Instead of implying an educative process that requires learners to go through various stages, Mozilla suggests that anyone can create and curate content for the web, regardless of their skills and background. Although one can question the motives behind this approach, Webmaker has contributed to making the Web accessible to more people. According to The Mozilla Blog (2013), more than 50,000 projects have been created on the site by people all around the globe (it is expected that the site will be translated in 40 languages).

I consider the Popcorn Maker to be ideal for the purposes of my educational research, as it is web based and easy for students who have no previous filmmaking experience, thus simplifying the workshops. Most of the programmes for the creation of interactive documentaries require coding skills, so the Popcorn Maker provides inexperienced users with an innovative way of creating interactive media.

Another popular programme for database films is Korsakow, an open-source application created by Berlin-based media artist Florian Thalhofer. The manifesto on the Korsakow website ${ }^{3}$ informs us: 'Korsakow Films are films with a twist: They are interactive - the viewer has influence on the K-Film. They are rule-based - the author decides on the rules by which the scenes relate to each other, but s/he does not create fixed paths. K-Films are generative - the order of the scenes is calculated while viewing.'

Korsakow requires no programming expertise and its downloadable version is available

\footnotetext{
${ }^{2}$ Available at https://popcorn.webmaker.org

${ }^{3}$ Available at http://korsakow.org
} 
for free, if used for educational purposes. Its interface is more complicated than the Popcorn Maker, but could provide an interesting alternative for teaching more advanced media students how to make interactive documentaries.

The Popcorn Maker was used by first year Media Production students at Coventry University in the context of their module under the title 'Creating Impact in Media Production'. The students were invited to experiment with different media platforms for the needs of the module, thus becoming familiar with the latest advancements in the field of New Media. One of their tasks was to create interactive documentaries of no longer than four minutes using the Popcorn Maker.

Some of the above mentioned students, who will remain anonymous, participated in a focus group interview, discussing different aspects of their experience using the Popcorn Maker. This focus group did not address issues related to the Freireian concept of critical consciousness, as the aim was to test the technical aspects of the tool before incorporating it in my fieldwork workshops. In the following, I will reflect on some of the most important points raised by the students.

The students characterized their overall experience using the Popcorn Maker useful, although they thought that parts of the process were frustrating. They summarized the main disadvantages of the tool in limited capability, as there is no undo or autosave function. The application kept crashing not only during the tutorial session but also when the students were trying to complete the tasks at their own pace. As a result, many students lost their projects and had to start from the beginning, thus discouraging them from using the software. These flaws are related to the fact that Popcorn Maker is still an early-stage application.

The biggest advantage of the tool was considered to be the fact that it is web based, and so anyone with a computer and internet access can use it. One of the students suggested launching a downloadable version, as this would allow users to link all projects in one file. The simplicity of the tool was also emphasized, as it reminded the students of basic editing techniques (dragging and dropping). This point is important for my fieldwork workshops, as the students do not have backgrounds in filming and editing.

At the start of the Popcorn Maker tutorial, the students had to remix a video of a user's Top-5 Nintendo games ${ }^{4}$. They were asked to create their Top-5 of their own favourite things. This exercise was selected in order to introduce the students to the interface and interactive features of the Popcorn Maker. The students found this exercise useful and similar to making a documentary in a way.

Regarding future workshops, the students suggested including more information on how to insert videos in the Popcorn Maker and how to solve the problems that may come up. It is also crucial not to raise the students' expectations before asking them to make their own interactive documentaries, as showing them sophisticated examples may give them

\footnotetext{
${ }^{4}$ Available at https://popcorn.webmaker.org/editor/33015/remix.
} 
the wrong impression that their films will look the same.

In general, the students agreed that the Popcorn Maker taught them about interactive documentaries, as they had never experienced them before. They also identified the problems with the process of creating but not of viewing a Popcorn Maker video. They thought that from the point of view of the user, a Popcorn Maker video is successful, as viewers can interact with the final product and have the power to learn at their own pace.

\section{Conclusion}

Interactive documentary is a powerful medium in the hands of young people and I am keen to evaluate its educational benefits. Mozilla's Popcorn Maker provides a good platform for creating interactive stories, despite the technical difficulties. This tool is suitable for educational purposes and addresses the democratic promise of Critical Media Education, as it is accessible by anyone and does not require students to have previous coding or editing experience.

Open Pedagogies and Critical Media Education provide frameworks for collaborative teaching and learning and address the democratizing potential of the Internet. The young people involved in my $\mathrm{PhD}$ fieldwork are encouraged to represent visions of the community, thus first understanding, and then being more capable of changing, the power dynamics embedded in it. In this respect, this process is aligned with the principles of Freire's pedagogy and its emphasis on 'Conscientization'.

It is envisaged that my $\mathrm{PhD}$ research project will provide a set of proposals for teaching and learning with interactive media, based on the results of the above mentioned workshops. This project will allow me to become familiar with all the issues that young people face in the process of making interactive documentary films, thus developing my teaching practice. The positive impact of my research on the young people involved is equally important for me, as they are encouraged to become agents of social change.

The author would like to thank Dr. Shaun Hides and Matthew Hawkins from Coventry University, for their valuable comments and support.

\section{References}

Buckingham, D. (2009) " "Creative" Visual Methods in Media Research: Possibilities, Problems and Proposals', Media, Culture and Society, 31 (4), 633-652

Buckingham, D. (2010) 'Do We Really Need Media Education 2.0: Teaching Media in the Age of Participatory Culture', Journal of Media Literacy, 57 (1-2), 18-27

Carr, W. \& Kemmis, S. (2009) 'Educational Action Research: A Critical Approach', in S. Noffke \& B. Somekh (eds), The Sage Handbook of Educational Action Research, London: Sage, pp. 74-84 
Delamont, S., \& Atkinson, P. (1980) 'The Two Traditions in Educational Ethnography: Sociology and Anthropology Compared', British Journal of Sociology of Education, 1, 139-152

Douzinas, C. (2013) Philosophy and Resistance in the Crisis, Cambridge: Polity

Favero, P. (2013) 'Getting our Hands Dirty (again): Interactive Documentaries and the Meaning of Images in the Digital Age', Journal of Material Culture 18 (3), 259-277 Freire, P. (1970) Pedagogy of Oppressed, New York: Continuum Galloway, D., Mcalpine, K. B., \& Harris, P. (2007) 'From Michael Moore to JFK Reloaded: Towards a Working Model of Interactive Documentary', Journal of Media Practice 8 (3), 325-339

Gifreu, A. (2011) 'The Interactive Documentary. Definition Proposal and Basic Features of the New Emerging Genre', in Proceeding of the McLuhan Galaxy Conference, held in Universitat Pompeu Fabra and Universitat Oberta de Catalunya, Spain.

Gifreu, A. (2012) 'The Interactive Nonfiction as 2.0 Educational Strategy. the Case of the Interactive Documentary', paper presented at the INTED conference, 05-07 March at, Valencia.

Goetz, J. \& Lecompte, M. (1984) Ethnography and Qualitative Design in Educational Research, Orlando: Academic Press

Hammer, R. (2009) 'This Won' t Be on the Final: Reflections on Teaching Critical Media Literacy', in R. Hammer \& D. Kellner (eds) Media/Cultural Studies: Critical Approaches, New York: Peter Lang Publishing

Jenkins, H., Purushotma, R., Clinton, K., Weigel, M., \& Robison, A. J. (2006) Confronting the Challenges of Participatory Culture: Media Education for the 21st Century [Online]. Available at http://mitpress.mit.edu/sites/default/files/titles/free_download/9780262513623_Con fronting the Challenges.pdf. Accessed 25 January 2015.

Jenkins, H. (2011) From New Media Literacies to New Media Expertise: "Confronting the Challenges of a Participatory Culture" Revisited [online]. Available from http://www.manifestoformediaeducation.co.uk/2011/01/henryjenkins/. Accessed 8 November 2014.

Jewitt, C (2012) 'An Introduction to Using Video for Research', NCRM Working Paper, NCRM. (Unpublished)

Kellner, D. \& Share, J. (2007) 'Critical Media Literacy, Democracy, and the Reconstruction of Education' in D. Macedo \& S. R. Steinberg (eds) Media Literacy: A Reader, New York: Peter Lang Publishing, pp. 3-23

Kellner, D. \& Kim, G. (2009) 'YouTube, Politics, and Pedagogy: Some Critical Reflections', in R. Hammer \& D. Kellner (eds) Media/Cultural studies: Critical Approaches, New York: Peter Lang Publishing

Kemmis, S. (1988) 'Action Research'. in Educational Research, Methodology, and Measurement: An International Handbook . ed. by Keeves, J. Oxford, England: Pergamon Press (na)

Kemmis, S. \& McTaggart, R. (2005) 'Participatory Action Research: Communicative Action and the Public Sphere' in N. Denzin \& Y. Lincoln (eds) Sage Handbook of Qualitative Research, Sage

Klein, S. \& Agostinone-Wilson, F. (2012) Action Research Methods: Plain and Simple, New York: Palgrave Macmillan 
Korsakow (no date) 'About' [online]. Available at http://korsakow.org/about/. Accessed 21 January 2015.

Manovich, L. (2001) The Language of New Media, Cambridge: The MIT Press

Poyntz, S. (2006) 'Independent Media, Youth Agency, and the Promise of Media Education', Canadian Journal of Education, 29 (1), 154-175.

Poyntz, S. (2011) Critical Citizenship and Media Literacy Futures [online]. Available from http://www.manifestoformediaeducation.co.uk/2011/06/stuart-poyntz/. Accessed 8 November 2014.

Mozilla Popcorn Maker (no date) 'Top 5 Nintendo Games Remix' [online]. Available at https://popcorn.webmaker.org/editor/33015/remix. Accessed 22 January 2015.

Sagor, R. (2011) The Action Research Guidebook: A Four-Stage Process for Educators and School Teams, Newbury Park: Corwin

The Mozilla Blog (2013) 'Webmaker: How the Mozilla Community is teaching the World the Web' [online]. Available at https://blog.mozilla.org/blog/2013/10/26/webmaker-how-the-mozilla-communityis-teaching-the-world-the-web/. Accessed 8 November 2014.

Wilson, S. (1977) 'The Use of Ethnographic Techniques in Educational Research', Review of Educational Research, 47 (1), 245-265

Woodbridge, P. (2011) 'Open Pedagogies in Creative Media: Moving from Knowledge Consumption to Exchange', paper presented at the Journal of Media Practice Annual Conference, Bristol, June 2011.

Danai Mikelli is a PhD candidate in the Department of Media, Coventry University. She studied Film at the School of Film Studies, Aristotle University of Thessaloniki and then completed her Master's degree in Documentary Practice at the University of Bristol. Her doctoral research concerns the use of interactive documentary as a tool in the hands of Critical Media pedagogues.

mikellid@uni.coventry.ac.uk 